\title{
LINFOMA CUTÁNEO DE CÉLULAS B TIPO CENTRO FOLICULAR CON INFILTRACIÓN A MÉDULA ÓSEA REPORTE DE UN CASO
}

\author{
Claudia Marcela Arenas Soto, $M D^{1}$, María Liliana Mariño Álvarez $M^{2}{ }^{2}$, Jorge Enrioue Calderón Gómez MD², \\ María Isabel González C $\mathrm{MD}^{3}$, Martha Patricia Robayo, $\mathrm{MD}^{4}$ \\ ${ }^{1}$ Dermatóloga, Universidad Militar Nueva Granada, Hospital Militar Central de Bogotá, Colombia. \\ ${ }^{2}$ Residente Dermatología, Universidad Militar Nueva Granada, Hospital Militar Central de Bogotá, Colombia. \\ ${ }^{3}$ Dermato-patóloga, Universidad Militar Nueva Granada, Hospital Militar Central de Bogotá, Colombia. \\ Departamento de Patología, Hospital Militar Central, Universidad Militar Nueva Granada, Bogotá, Colombia. \\ ${ }^{4}$ Dermatóloga, Universidad Militar Nueva Granada, Hospital Militar Central de Bogotá, Colombia. \\ Departamento de Dermatología, Hospital Militar Central, Universidad Militar Nueva Granada, Bogotá, Colombia.
}

\begin{abstract}
Resumen
Los linfomas cutáneos primarios de células B constituyen cerca del 20-25\% de todos los linfomas. El linfoma cutáneo primario de células B tipo centro folicular es el subtipo más frecuente y se manifiesta principalmente en pacientes adultos con una edad media de 58 años (1), la diseminación extra-cutánea es muy rara y se presenta con nódulos, tumores o placas solitarios o en grupo usualmente localizados en cabeza o tronco. Presentamos el caso de una paciente con un linfoma primario cutáneo tipo centro folicular con infiltración a médula ósea.
\end{abstract}

Palabras clave: Linfomas cutáneos de células B, linfoma centro folicular.

\section{PRIMARY CUTANEOUS FOLLICLE CENTER LYMPHOMA WITH BONE MARROW INFILTRATION}

\begin{abstract}
Primary B cell cutaneous lymphomas represent approximately 20-25\% of all lymphomas. Primary cutaneous follicle center lymphoma is the most common subtype occurring in adults with a mean age of 58 years. The disease typically presents with solitary plaques or nodules and is usually located in the head or trunk. Extra cutaneous dissemination is extremely rare. We present a case of a patient with primary cutaneous follicle center lymphoma with bone marrow infiltration.
\end{abstract}

Key words: Cutaneous B-cell lymphoma, primary cutaneous follicle center lymphoma

* marialilianam@gmail.com 3013364180 


\title{
LINFOMA CUTÂNEO DE CÉLULAS B TIPO CENTRO FOLICULAR COM INFILTRAÇÃO NA MEDULA ÓSSEA, RELATÓRIO DE UM CASO
}

\begin{abstract}
Resumo
Os linfomas cutâneos primários de células B constituem cerca de 20 a $25 \%$ de todos os linfomas. O linfoma cutâneo primário de células $\mathrm{B}$ tipo centro folicular é o subtipo mais frequente e manifesta-se principalmente em pacientes adultos com uma idade média de 58 anos (1), a disseminação extracutânea é muito rara e apresenta-se com nódulos, tumores ou placas solitárias no grupo usualmente localizados na cabeça ou tronco. Apresentamos o caso de uma paciente com um linfoma primário cutâneo tipo centro folicular com infiltração na medula óssea.
\end{abstract}

Palavras chave: Linfomas cutâneos de células B, linfoma centro folicular.

\section{Caso clínico}

Paciente femenina de 68 años con único antecedente de Diabetes Mellitus en tratamiento con insulina, quien consulta por cuadro clínico de 6 meses de evolución de aparición de masa tumoral en región parieto-occipital, no dolorosa, con aumento de tamaño. La paciente consultó en múltiples ocasiones a medicina general y urgencias, donde realizan impresión diagnóstica de hematoma contenido por trauma de tejidos blandos y dan salida con analgésicos y antiinflamatorios. Posteriormente paciente re-consulta a urgencias por persistencia de masa y con impresión diagnóstica de absceso de tejidos blandos recibe tratamiento antibiótico sistémico. Por crecimiento progresivo de la lesión, e inicio de dolor tipo picada la paciente consulta nuevamente. Al examen físico se observa en región coronal tumor de bordes regulares asimétricos, eritematoso, infiltrado, de $5 \times 5 \mathrm{~cm}$ de diámetro y costra meliflua central asociado a alopecia (Figura 1 y 2). Se realiza biopsia de piel la cual reporta: linfoma no Hodgkin difuso de célula grande $\mathrm{B}$ tipo centro germinal (Figura 3 y 4). Se realiza inmunohistoquímica, en la cual las células tumorales son positivas para antígeno común leucocitario, CD20, CD79 y BCL6, vimentina y marcación ambigua con S100; con un índice de proliferación tumoral Ki67 de aproximadamente el 80\%. (Figuras 5 a-d). Las células tumorales son negativas para citoqueratina $\mathrm{AE} 1 / \mathrm{AE} 3$, citoqueratina 20, CD3, CD5, CD30, CD10, CICLIN D1 y HMB45.

Con las características clínicas e histológicas se realiza una impresión diagnostica de LINFOMA CUTÁNEO DE CÉLULAS B DIFUSO TIPO CENTRO GERMINAL. Se realizan paraclínicos complementarios, el

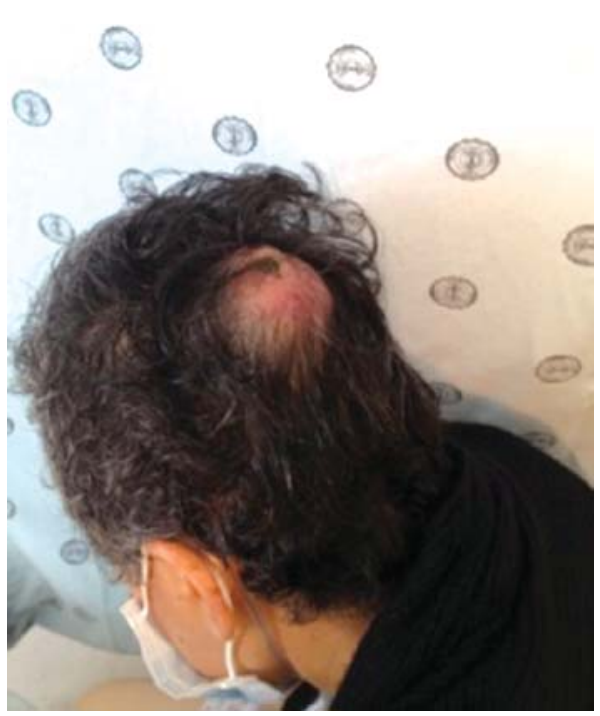

Figura 1.



Figura 2. 


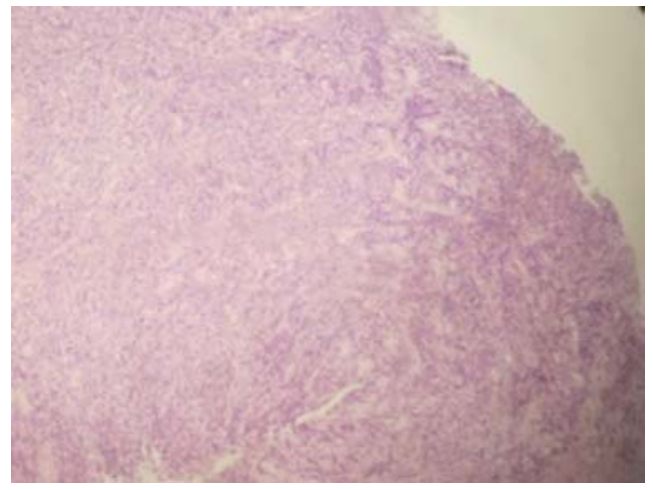

Figura 3. $H \& E 10 x$

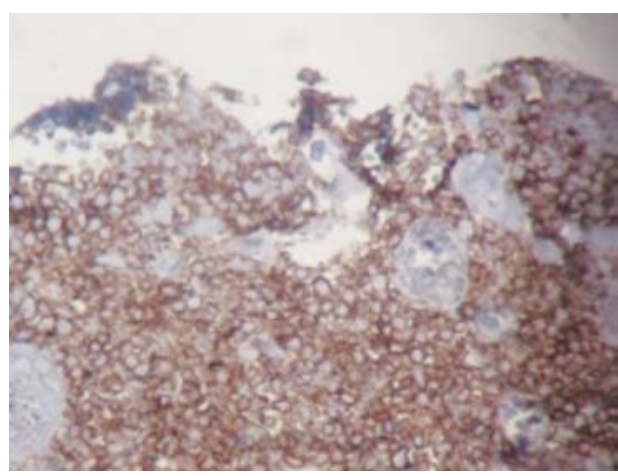

Figura 5A. Antígeno Común Leucocitario

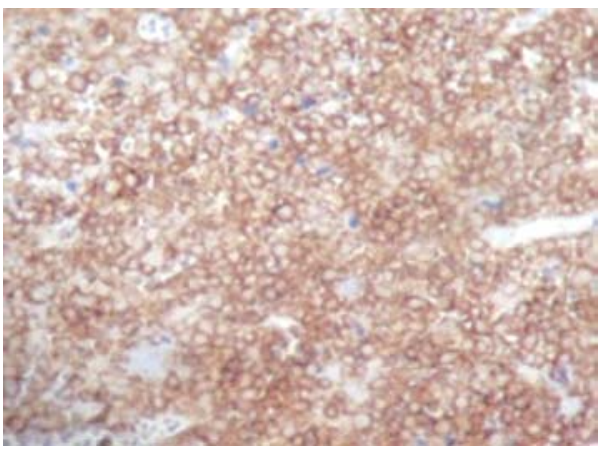

Figura 5C. CD79

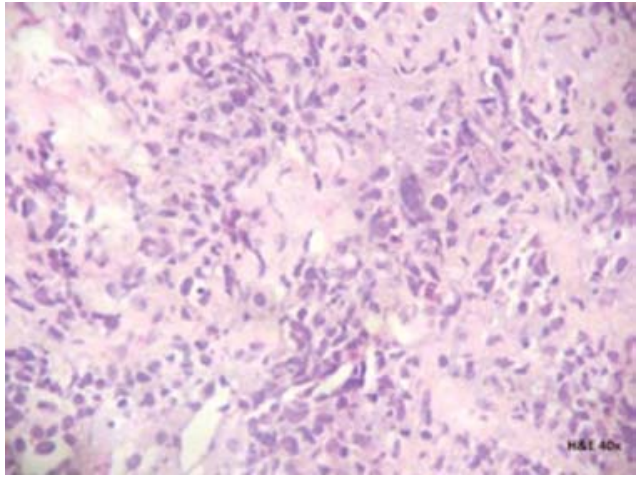

Figura 4. H\&E $40 x$

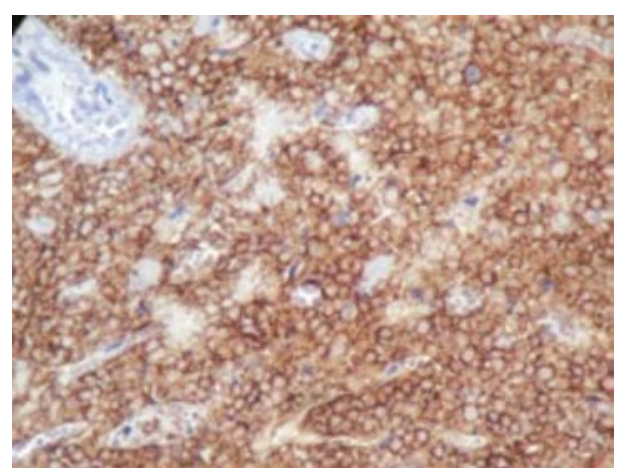

Figura 5B. CD20

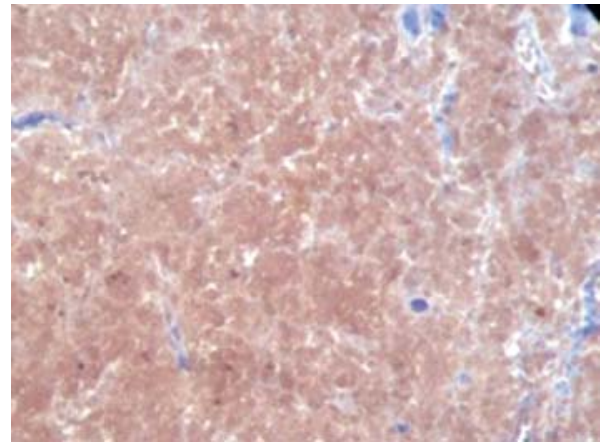

Figura 5D. BCL6

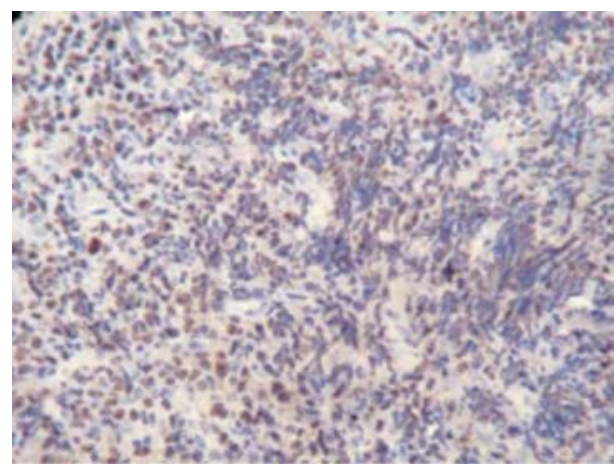

Figura 5E. Vimentina 


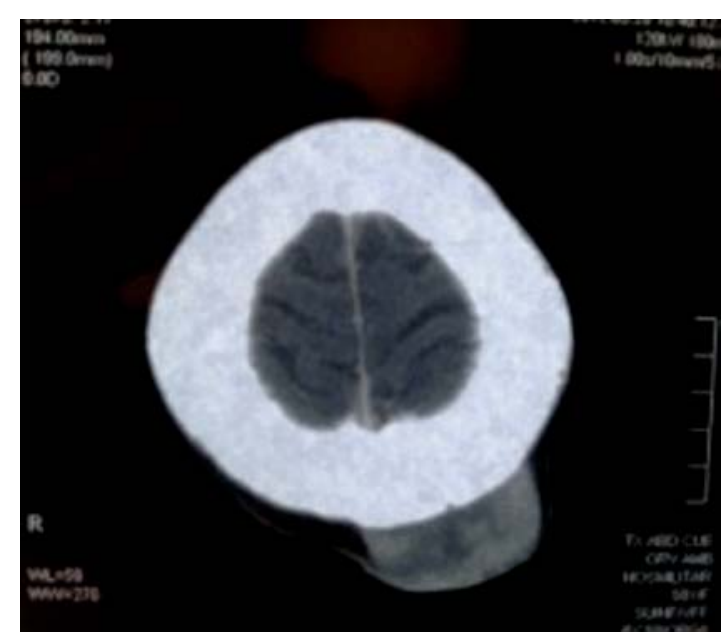

Figura 6A. TAC cráneo simple

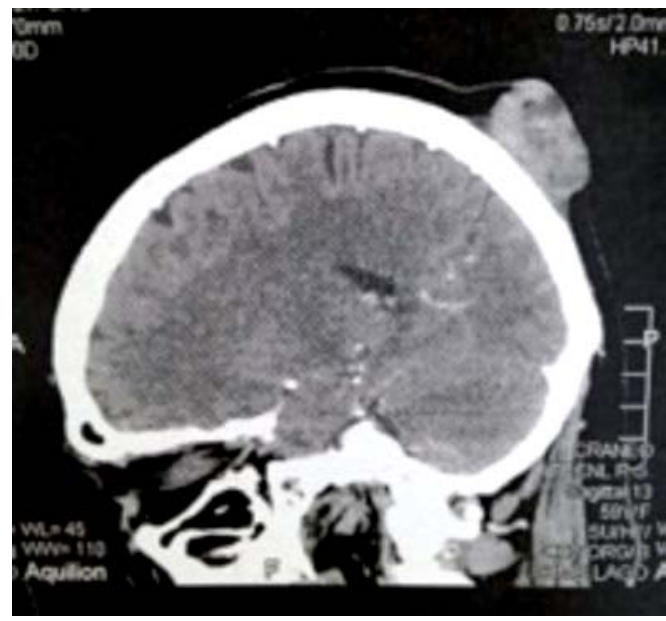

Figura 7B. hemograma revela pancitopenia severa, en la TAC de cráneo con contraste se observa masa en tejidos blandos extra-craneales parietales izquierdos (Figura $6 a$ y 6b). TAC de cuello donde se evidencian múltiples adenomegalias, TAC de tórax que evidencia masa retrocrural inespecífica y TAC de abdomen con esplenomegalia. Debido a la pancitopenia severa se realiza biopsia de médula ósea la cual muestra infiltración por neoplasia hematolinfoide de célula grande. Con el mismo inmunofenotipo del tumor del cuero cabelludo, con CD10, CD138, CD30, y TDT negativas y Ki67 del 15\%. La paciente es tratada multidisciplinariamente por oncología y cirugía general y se plantea como tratamiento inicial quimioterapia con infliximab seguido de radioterapia debido a la infiltración extra-cutánea del linfoma y estado activo del mismo. Previo al inicio del tratamiento, durante la estancia hospitalaria, la paciente fallece debido sepsis severa secundaria a la pancitopenia derivada de la infiltración tumoral de la médula ósea.

\section{Discusión}

Los linfomas cutáneos primarios de células B constituyen del 20-25\% de todos los linfomas cutáneos primarios, (2) y hacen parte de un grupo poco común de enfermedades linfoproliferativas de células B, cuya manifestación es limitada a piel y la diseminación extra-cutánea es rara $(3,4)$. Los linfomas cutáneos han sido clasificados por la WorldHealthOrganization, (WHO por sus siglas en inglés) en 3 tipos principales teniendo encuentra su histología y patrón molecular: linfoma cutáneo primario tipo zona marginal, linfoma cutáneo centro folicular y el linfoma cutáneo de célula grande $\mathrm{B}$ difuso tipo pierna $(3,5)$. Para el diagnósti$\mathrm{co}$, se realiza con frecuencia la biopsia incisional o escisional. El panel diagnóstico de anticuerpos contra antígenos de célula B incluye CD5, CD10, CD20, CD79, BCL-2, BCL-6, kappa/lambda y MUM1.

Entre los estudios complementarios se debe realizar hemograma, LDH (deshidrogenasa láctica), citometría de flujo en sangre periférica, Tomografía Axial Computarizada (TAC) de tórax, abdomen y pelvis con contraste.

Tradicionalmente el término de linfoma cutáneo primario solo se aplica cuando los estudios complementarios son negativos al momento del diagnóstico y cuando permanecen negativos por 6 meses adicionales (3).Sin embargo, esto ha sido debatido debido a que en casos de formas agresivas de linfomas cutáneos primarios se pueden diseminar rápidamente a forma sistémica. En nuestro caso se plantea la hipótesis que se trató de un linfoma cutáneo primario con diseminación sistémica rápida, con infiltración a médula ósea y debido que hubo demora en el diagnóstico, planteamos que los 6 meses de evolución que refería la paciente del cuadro clínico fueron determinantes para la diseminación sistémica del linfoma cutáneo.

Algunos autores han planteado la realización de biopsia por médula ósea con los paraclínicos de rutina, mientras que otros plantean que se debe realizar solo en pacientes con grado intermedio de linfoma prima- 
rio cutáneo de células $\mathrm{B}$, debido a la baja frecuencia de biopsias positivas de médula ósea reportadas (5.2\%) (6). La diseminación a médula ósea en un estudio retrospectivo de 57 sujetos fue positivo en 3 pacientes, siendo dos de ellos linfoma cutáneo primario de célula B tipo centro folicular y el restante tipo cutáneo marginal, y tan solo 3 estudios hablan de la realización de biopsia de médula ósea como procedimiento de rutina $(6,8)$. Así mismo una biopsia positiva cambia tanto el pronóstico, sobrevida y tratamiento a seguir. En el presente caso se realizó biopsia de médula ósea debido a que se encontró un linfoma con perfil activado dado por su índice de proliferación de Ki67 de $80 \%$, así mismo por la pancitopenia encontrada en los paraclínicos complementarios.

El linfoma cutáneo primario de célula B tipo centro foliculares el subtipo más común de los linfomas cutáneos primarios de células $\mathrm{B}$, constituyendo cerca del $55 \%$ de los mismos.Se manifiesta en una edad media de 58 años siendo más frecuente en mujeres que en hombres en una proporción 2:1 teniendo una sobrevida a 5 años del 95\% (4,9); mientras que la tasa de recaídas es del 30\% (2). Las manifestaciones cutáneas pueden ser pápulas o nódulos pardo-eritematosos y su localización más frecuente se encuentra en cabeza, cuero cabelludo y tronco $(1,4)$.

El diagnóstico de linfoma cutáneo primario de célula $\mathrm{B}$ tipo centro folicular incluye criterios histopatológico se inmunohistoquímicos y constituye uno de los aspectos más difíciles en dermatopatología.El linfoma cutáneo primario de célula $\mathrm{B}$ tipo centro folicular representa un espectro de patrón nodal, nodal y difuso o difuso con proporciones variables de centrocitos pequeños y centroblastos, y a veces un patrón de crecimiento folicular en las lesiones tempranas; mientras que en las lesiones tumorales avanzadas presenta infiltrados difusos de centrocitos grandes con ausencia de epidermotropismo $(10,11)$.

En inmunohistoquímica las células malignas son positivas para CD19, CD20, CD22, CD79 y BCL6. La expresión de CD10 suele ser positiva en lesiones con patrón de crecimiento folicular pero negativas en lesiones con patrón de crecimiento difuso, como es el caso de nuestro paciente. La expresión de BCL-2 y MUM1/IRF4 es detectada en cerca del 10\% de los pacientes $(1,4)$. La expresión de Ki67 es característica en linfoma con perfil activado, en nuestro caso el Ki67 fue del 80\%.
La diferenciación del linfoma cutáneo de célula B tipo centro folicular y el linfoma cutáneo de célula B grande difuso tipo pierna ha sido controversial debido a que los patrones encontrados en inmunohistoquímica se sobreponen entre los dos y han dado lugar a múltiples discusiones en cuanto a su diagnóstico. Con los nuevos avances en la biología molecular, se han encontrado diferencias en el linfoma cutáneo de célula B tipo centro germinal como aberraciones en amplificaciones en el DNA, siendo la más frecuente en $2 \mathrm{p} 16.1$ y deleciones de cromosomas 14q32.33 la cual explicaría la perdida de expresión de RNAm que codifica para la cadena pesada de la inmunoglobulina, siendo uno de los factores de diferenciación más importantes con el linfoma cutáneo de célula grande difuso tipo pierna (11).

El tratamiento de elección para el linfoma cutáneo primario de células $\mathrm{B}$ se basa en la histología, la localización anatómica y el número de lesiones tumorales. El linfoma de bajo grado puede ser manejado con escisión y radioterapia mientras que el grado intermedio requiere quimioterapia más radioterapia. Se han descrito tratamientos con monoterapia sistémica con rituximab para el cual ha sido reportada una respuesta favorable en el linfoma cutáneo de células B tipo centro germinal con tasas de curación del $80 \%$ (12). En cuanto a rituximab intralesional ha mostrado respuesta favorable entre el 60 al 100\%, aunque son estudios con muestras pequeñas (4).Para el linfoma cutáneo de células B tipo centro germinal el tratamiento de primera línea es radioterapia, mientras que la quimioterapia es reservada para pacientes con diseminación extra-cutánea o con lesiones cutáneas extensas (13). Debido al fallecimiento de la paciente no se logró iniciar el esquema propuesto de quimioterapia, infliximab más radioterapia.

\section{Conclusión}

El linfoma cutáneo primario de célula B tipo centro germinal constituye una patología poco frecuente en dermatología, sin embargo, es el tipo más predominante de linfomas cutáneos de células $\mathrm{B}$, afectando a adultos mayores y ancianos, por lo cual debe ser incluido dentro de los posibles diagnósticos diferenciales en el momento de la valoración inicial de un adulto mayor con lesiones nodulares únicas o múltiples en cuero cabelludo, cabeza y tronco. Un diagnóstico oportuno es clave para mejorar la sobrevida del paciente. Así mismo, la infiltración a tejidos extracutáneos del linfoma cutáneo de células B tipo 
centro germinal es extremadamente infrecuente, por lo cual entre los paraclínicos complementarios la biopsia de médula ósea no es mandatoria, solamente en casos de linfomas de grado intermedio o en linfomas activos. Reportamos el caso de una paciente femenina con linfoma cutáneo de células B con compromiso neoplásico de médula ósea.

\section{Referencias bibliográficas}

1. Senff NJ, Hoefnagel JJ, Jansen PM, Vermeer MH, van Baarlen J, Blokx WA, et al. Reclassification of 300 primary cutaneous B-Cell lymphomas according to the new WHO-EORTC classification for cutaneous lymphomas: comparison with previous classifications and identification of prognostic markers. J. Clin. Oncol. 2007;25(12): 1581-7.

2. Senff NJ, Noordijk EM, Kim YH, Bagot M, Berti E, Cerroni $\mathrm{L}$, et al. European organization for research and treatment of cancer and international society for cutaneous lymphoma consensus recommendations for the management of cutaneous b-cell lymphomas. Blood. 2008;112(5): 1600-9.

3. Willemze R, Jaffe ES, Burg G, Cerroni L, Berti E, Swerdlow $\mathrm{SH}$, et al. WHO-EORTC classification for cutaneous lymphomas. Blood. 2005;105(10): 3768-85.

4. Sokol L, Naghashpour M, Glass LF. Primary cutaneous B-cell lymphomas: recent advances in diagnosis and management. Cancer Control. 2012;19(3): 236-44.

5. Jaffe ES. The 2008 WHO classification of lymphomas: implications for clinical practice and translational research. Hematology Am Soc Hematol Educ Program. 2009; 523-31.
6. Quereux G, Frot AS, Brocard A, Leux C, Renaut J-J, Dreno $\mathrm{B}$. Routine bone marrow biopsy in the initial evaluation of primary cutaneous B-cell lymphoma does not appear justified. Eur J Dermatol. 2009;19(3): 216-20.

7. Wejroch MP, Cornillet P, Perceau G, Durlach A, Bernard $P$. [Frequency of associated malignancies in cutaneous lymphomas: a retrospective study of 86 cases]. Ann Dermatol Venereol. 2004;131(4): 339-45.

8. Yasukawa K, Kato N, Kodama K, Hamasaka A, Hata H. The spectrum of cutaneous lymphomas in Japan: a study of 62 cases based on the World Health Organization Classification. J. Cutan. Pathol. 2006;33(7): 487-91.

9. Hallermann C, Niermann C, Fischer R-J, Schulze H-J. Survival data for 299 patients with primary cutaneous lymphomas: a monocentre study. Acta Derm. Venereol. 2011;91(5):521-5.

10. Willemze R, Meijer CJ, Scheffer E, Kluin PM, van Vloten WA, Toonstra J, et al. Diffuse large cell lymphomas of follicular center cell origin presenting in the skin. A clinicopathologic and immunologic study of 16 patients. Am. J. Pathol. 1987; 126 (2): 325-33.

11. Dijkman R, Tensen CP, Jordanova ES, Knijnenburg J, Hoefnagel JJ, Mulder AA, et al. Array-based comparative genomic hybridization analysis reveals recurrent chromosomal alterations and prognostic parameters in primary cutaneous large B-cell lymphoma. J. Clin. Oncol. 2006; 24(2): 296-305.

12. Morales AV, Advani R, Horwitz SM, Riaz N, Reddy S, Hoppe $\mathrm{RT}$, et al. Indolent primary cutaneous B-cell lymphoma: experience using systemic rituximab. J. Am. Acad. Dermatol. 2008;59 (6): 953-7.

13. Fernandez-Flores A, Smucler-Simonovich A, Escalante F, Manjon JA. The differential diagnosis between primary cutaneous large B-cell lymphoma and cutaneous follicular lymphoma: prognostic and therapeutic implications. Am J Dermatopathol 2011; 33(8): 819-26. 